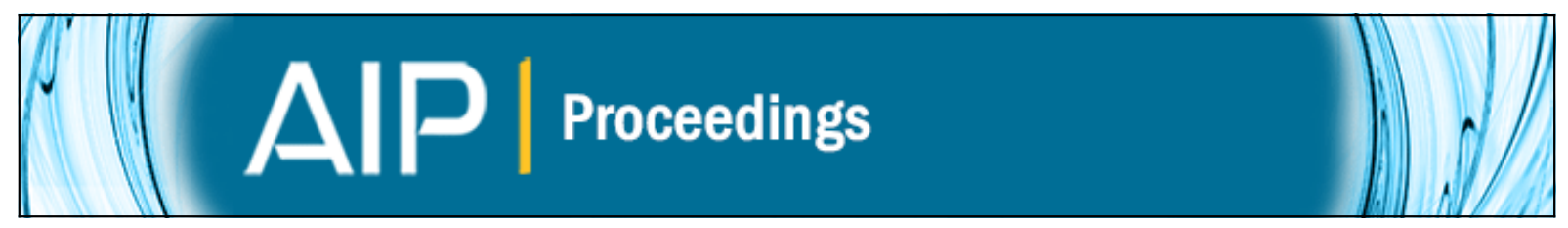

\title{
Electronic journals: Their use by teachers/researchers of engineering and social
} \section{sciences}

Fernanda Martins, Diana Machado, Alberto Fernandes, and Fernanda Ribeiro

Citation: AIP Conference Proceedings 1644, 17 (2015); doi: 10.1063/1.4907812

View online: http://dx.doi.org/10.1063/1.4907812

View Table of Contents: http://scitation.aip.org/content/aip/proceeding/aipcp/1644?ver=pdfcov

Published by the AIP Publishing

\section{Articles you may be interested in}

Research and the training of physical science teachers in South Africa

AIP Conf. Proc. 399, 327 (1997); 10.1063/1.53138

Earthquake Engineering Research Center Publishes Abstract Journal in Earthquake Engineering

J. Acoust. Soc. Am. 69, 608 (1981); 10.1121/1.385455

Electronics Research and Engineering

Phys. Today 13, 84 (1960); 10.1063/1.3057026

Schoolchildren publish bee research in science journal

Phys. Today

Koonin sees social sciences as key to future research

Phys. Today ; 10.1063/PT.4.0580 


\title{
Electronic Journals: Their Use By Teachers/Researchers Of Engineering And Social Sciences
}

\author{
Fernanda Martins, ${ }^{1, a)}$ Diana Machado ${ }^{1}$, Alberto Fernandes ${ }^{1}$ and Fernanda Ribeiro ${ }^{1}$ \\ ${ }^{1}$ Faculdade de Letras da Universidade do Porto \\ a) Corresponding author: mmartins@letras.up.pt
}

\begin{abstract}
Libraries must attend the needs of their different users. Academics are usually a particular kind of users with specific needs. Universities are environments where scientific communication is essential and where electronic format of journals is becoming more and more frequently used. This way it becomes increasingly important to understand how academics from different scientific areas use the available electronic resources. The aim of this study is to better understand the existing differences among the users of electronic journals in Engineering and Social Sciences. The research undertaken was mainly focused on the study of the use of electronic journals by teachers/researchers from the Faculties of Engineering and of Arts from the University of Porto, Portugal. In this study an international survey was used in order to characterize the levels of use and access of electronic journals by these communities. The ways of seeking and using scientific information, namely in terms frequency of access, the number of articles consulted, the use of databases and the preference of publishing in electronic journals were analyzed. A set of comparisons were established and results indicate an extensive use of the electronic format, regardless the faculty. However, some differences emerge when it comes to details. Such is the case of the usage rate of reference management software which is considerably more used by Engineering academics than Social Science ones. Generally, electronic journals meeting the information needs of its users and are increasingly used as a preferred means of research. Though, some particular differences in the use of them have emerged, when comparing academics from these two faculties.
\end{abstract}

\section{INTRODUCTION}

Over centuries, Science and its ways of communicating have suffered grate changes. From correspondence exchanges in the first centuries to scientific journals and to the presently known electronic format, communication has been involved.

Currently, with the advent of information and communication technology, along with the high production rate of scientific information, the field of information behavior has been the subject of a great number of studies. This brought to light the many existent differences between the various scientific areas. The present study will address the topic of information behavior regarding the use of electronic journals displayed by teachers and researchers of two distinct areas: Engineering and Social Sciences.

\section{ELECTRONIC JOURNALS AND INFORMATION BEHAVIOUR}

\section{Electronic Journals}

In the beginning of scientific communication, scientists used to communicate through correspondence. However, the small audience being reached by those letters, along with the amount of time it took to exchange them was not satisfactory (Stumpf, 1996).

A few centuries later, when the first Academies of Science were founded, the first scientific conferences started being organized. At that time, reports were done describing everything that happened, along with every finding that was disclosed and reviewed.

International Conference on Integrated Information (IC-ININFO 2014)

AIP Conf. Proc. 1644, 17-23 (2015); doi: 10.1063/1.4907812

(C) 2015 AIP Publishing LLC 978-0-7354-1283-5/ $\$ 30.00$ 
These reports were then handed to all those interested (Stumpf, 1996; Castillo et al., 2010). The first scientific journal, the Journal des Sçavans, later renamed Journal des Savants emerged in 1665. It was published in Paris, with weekly issues (Stumpf, 1996; Castillo et al., 2010). Some other journals appeared also in Germany and Italy, but their publication was discontinued for not being in accordance with the standards of the time (Stumpf, 1996). This was the reason why, only in the 19th century scientific journals earned credibility enough to surpass books (Menezes et al., 1999). The increase in the number of electronic publications in the 1960s led to the first attempts at replacing paper publishing for electronic publishing. Nevertheless, these attempts were successful only in the following decades in a way that in 1987 there were over a thousand titles available online (Stumpf, 1996; Menezes et al., 1999).

It wasn't easy introducing digital technology in the scientific world. Some researchers were skeptical towards these advances and regarded the works published in the electronic environment as doubtful (Mueller and Passos 2000). Nonetheless the new level of accessibility, as well as, the lower cost, the possibility of publishing faster, even innovative and heterodox work, the interactivity and the new formats were advantages in favor of electronic format (Borges, 2006).

Nowadays, electronic publishing also allows a quick and constant way to access articles.

Thus the early ways of correspondence exchange suffered changes that that have led to the emergence of scientific journals in electronic format as we know them today gathering in a single publication numerous authors and studies (Meadows, 1974; Barbalho, 2005)

\section{Informational Behavior}

The study of informational behavior is crucial to understand the entire process that involves a set of actions starting with the production and going to the use of scientific information.

For a better understanding of this whole process, it is important to define the concept of informational behavior as well as the information requirements, since they are related to the professional activities of each individual.

Informational behavior is a "way of being or react to a person or a group in a given situation and context, driven by needs induced and spontaneous, with regard solely to the production/broadcasting, reception, memorization/storage, reproduction and dissemination of information" (Silva 2006). It is necessarily related with the concept of informational need that, according to Wilson (1981), describes a subjective experience that occurs only in the mind of each individual, and is not directly accessible to the observer. This need can only be discovered by deduction, through the behavior, or by an act of enunciation of the person who holds it.

Wilson (1981) typifies the needs in physiological, cognitive and affective ones and points out that, in the case of informational needs, there are also "reasons" at the origin and as causes for the expressed behaviors.

\section{Differences between Engineering and Human and Social Sciences}

Informational behavior is different depending on the scientific area it is related to, which mean that each study area presents different specificities and characteristics.

Researchers differ attending to preferences in the communication channels they use as well as in how they produce knowledge. Muller (2005) states that, the preference demonstrated by researchers "reflects the prestige or value that researchers ascribe to various channels of communication and dissemination".

In the context of this study and having as object of study the informational behavior of researchers from two distinct areas - Engineers and Human and Social scientists- it is important to point out the major differences that set them apart.

In comparison to Human and Social scientists, Engineers adopt different information seeking habits, practices, needs and preferences. Unlike Human and Social scientists, Engineers are worried about producing, designing products, processes or systems other than to contribute to the development of the scientific literature. They normally work with time limits, which make them less interested in theories and rather with practical answers to real problems. This is like a psychological trait that makes them try to solve problems by themselves. Engineers when compared with Human and Social scientists, use libraries less frequently and use only information systems oriented for them (Pinelli, 1991). They have the tendency to read small books, standards, specifications and technical reports, as they are looking for specific answers and formulas intelligible to them. They do not want big collections of documents that have to be evaluated and translated before applying. 
Regarding informational behavior, and according to Pinelli (1991), Engineers follow the "law of least effort" achieving a goal with the minimum possible effort. For them accessibility is the most important factor in terms of informational behavior followed by the technical quality of the sources. In the same sense there needs are strongly influenced by experience.

The study of Herner (1954) is one of the first focusing specifically on the differences between habits and research information. This author points out significant differences in the performance of basic researchers and academics. The main differences between Engineers and Scientists depend on their philosophies and habits. Engineers also prefer the personal contact to generate ideas than the technical literature as well as unpublished reports (Pinelli, 1991).

\section{METHODOLOGY}

The main objective of this study was to analyze and eventually distinguish the level of use and access of electronic journals by the community of teachers/researchers from two different colleges from the University of Oporto: the Faculty of Engineering (FEUP) and the Faculty of Arts and Humanities (FLUP).

\section{Participants}

In this study the sample was composed of a total of 130 individuals, 53 from FEUP representing $41 \%$ of the total and 77 from the Faculty of Arts and Humanities representing 59\% (Figure 1).

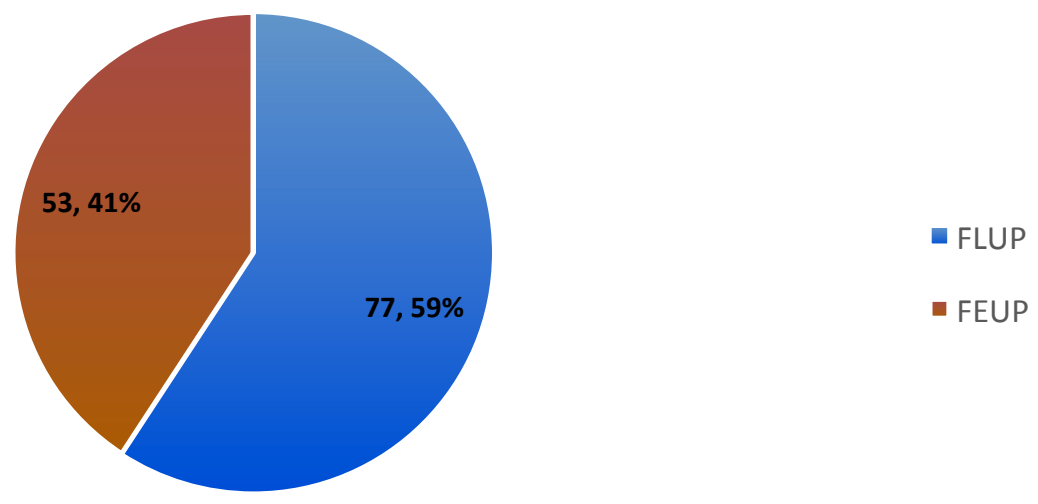

FIGURE 1. Participants

\section{Materials}

A survey was applied that was composed by 28 questions with response options and 3 opened questions. This survey was created specifically for this study and it was similar to the one applied in the University of Leon in Spain and in the University of Coimbra in Portugal both engaged in a more comprehensive study. Some adaptations were made particularly on "demographic data" section.

It has been tested by a small sample of individuals and some adjustments were made before being applied. The questionnaire has been placed on an online platform (questionpro.com).

\section{RESULTS}

A comparative study between the two Faculties has been made. Results indicate that in general there is much similarity on the responses of the two different faculties. Nevertheless some differences appeared related to the knowledge and use of the existing electronic journals resources by lecturers. 
Concerning the "Habits and accesses" to electronic journals, the majority of the participants knows and uses this resource with FEUP presenting a percentage of $94,3 \%$ of teachers/researchers answered affirmatively and FLUP $98,7 \%$.

Regarding the "Access and use of electronic journals provided by the Faculty", there are percentage differences on the options "I have the appropriate knowledge to access electronic journals". Thus, there is a significant association between Faculty and the knowledge to access and use of electronic journals available at the University $(\chi 2(1)=4,213, \mathrm{p}=0,040)$ (Figure 2).

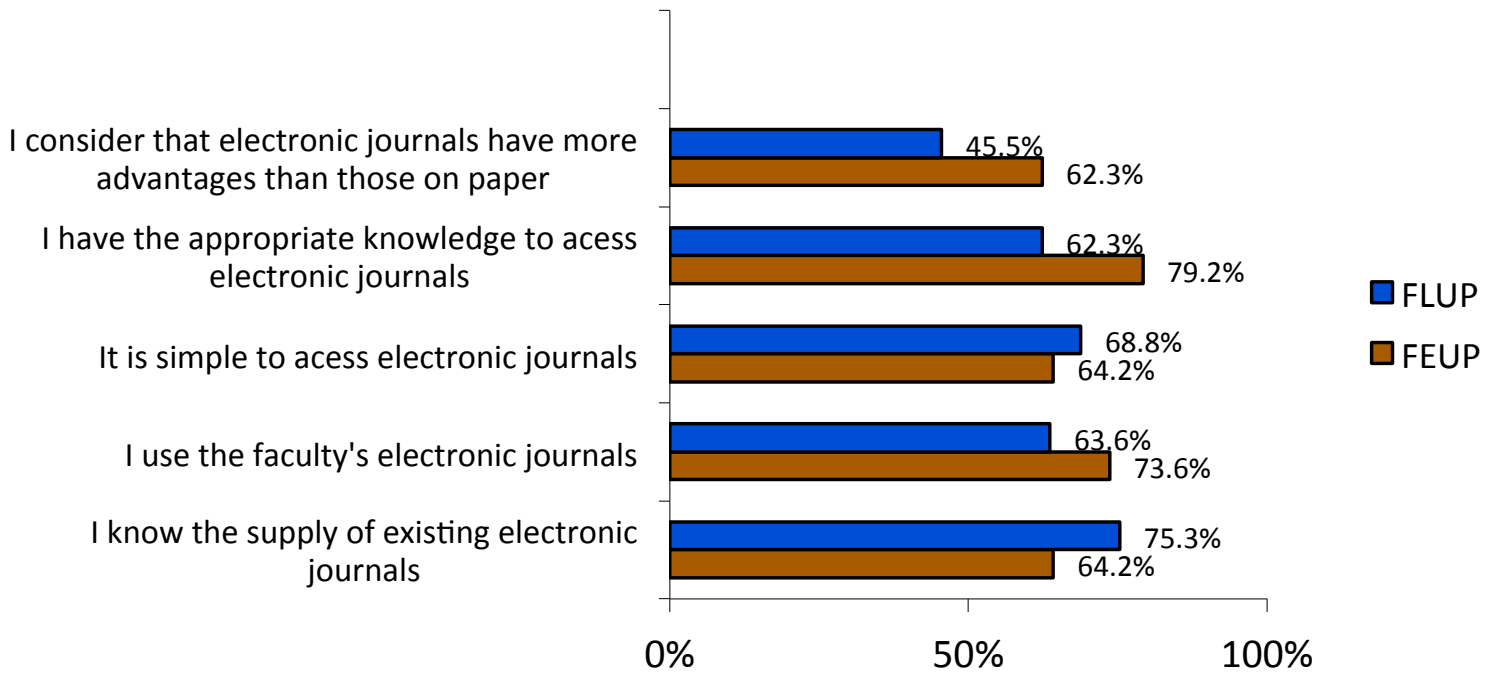

FIGURE 2. Access and use of electronic journals

Differences between the reasons why teachers/researchers choose to use electronic journals show that "Greater availability of electronic articles than printed ones" was chosen in a larger percentage by the FLUP teachers/researchers. There was a significant association between Faculty and that reason $(\chi 2(1)=3,902, p=0,048)$ (Figure 3).

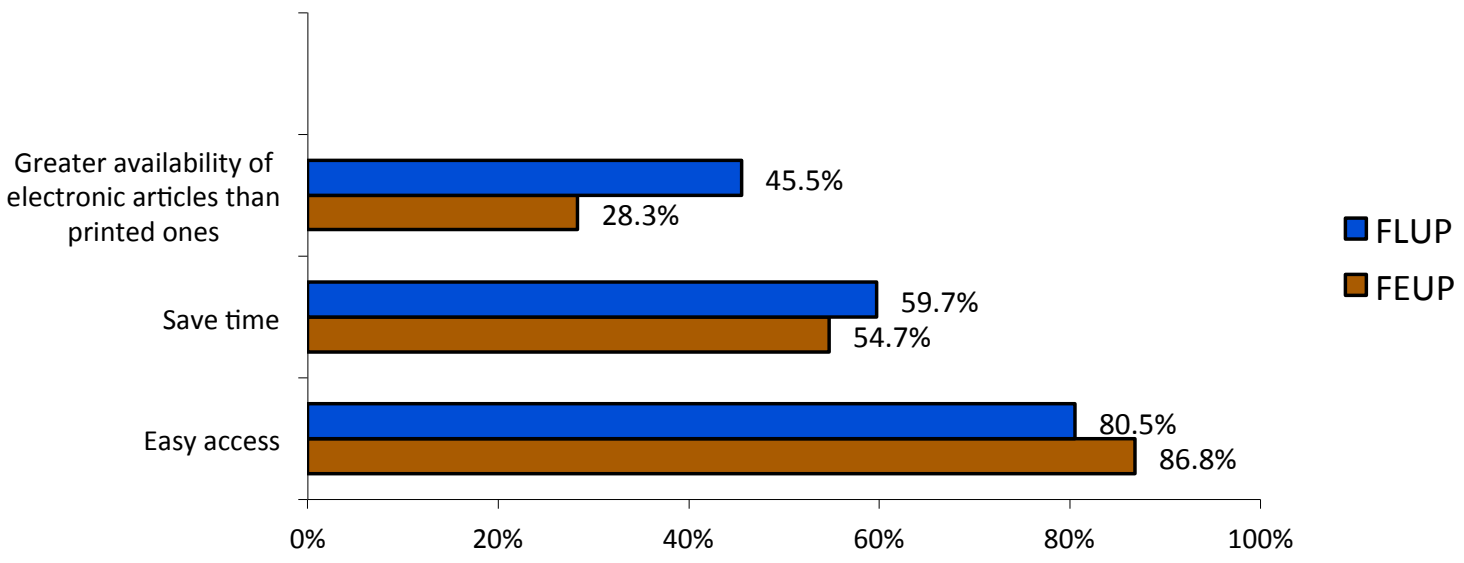

FIGURE 3. Reasons for the use of electronic journals

Concerning the access of electronic contents there is a difference in the level of the use of the website of the Library of the respective Faculty. They are most used by teachers/researchers from FLUP (76,6\%). In FEUP only $52,8 \%$ of the respondents use this way of accessing contents. Thus, there is a significant association between Faculty and the access of contents through the Library website $\left(\chi^{2}(1)=8,028, p=0,005\right)$ as presented in Figure 4. 


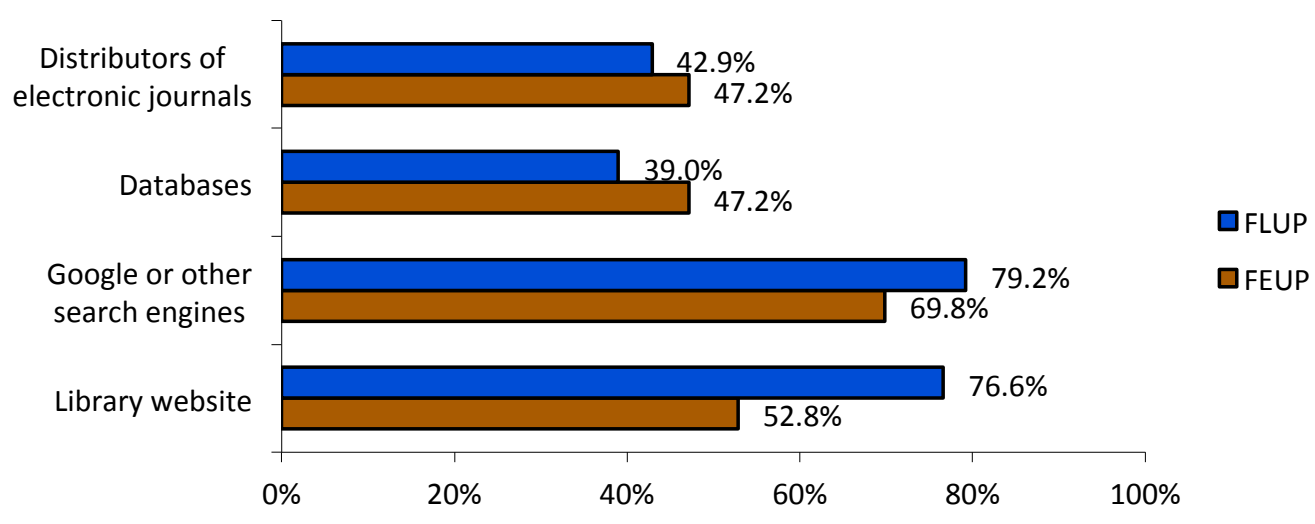

FIGURE 4. Ways of accessing electronic contents

Analysing the frequency of access to electronic journals there is a significant difference between the two Faculties. Teachers/researchers from FEUP use with greater regularity electronic journals, with about $32 \%$ of the respondents doing it daily against $5,3 \%$ at FLUP. Also in this case it was observed a significant association between Faculty and the frequency of access to electronic journals $(\chi 2(4)=27,66, p=0,000)$ (Figure5).

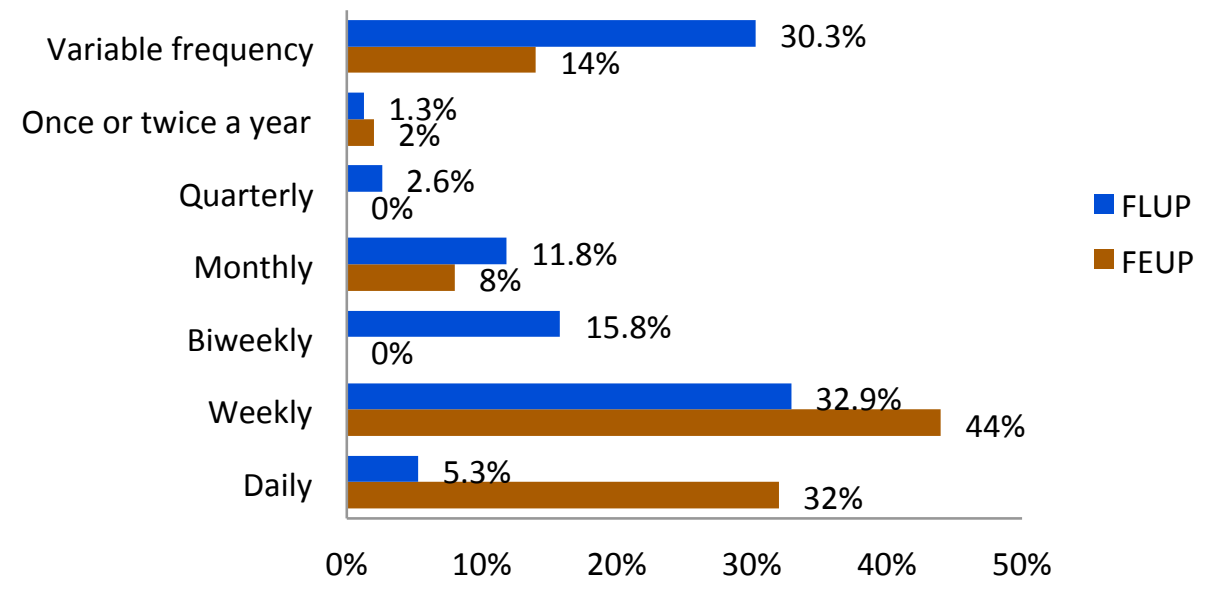

FIGURE5. Frequency of access to electronic journals

Analysing if there is a period of the school year that is preferable to access this type of information, teachers/researchers from FLUP prefer the period with lessons, with 30,3\% against $8 \%$ from the FEUP. Also in this case it was observed a significant association between Faculty and the preferred period to access electronic journals $(\chi 2(3)=18,006, p=0,000)$ (Figure 6).

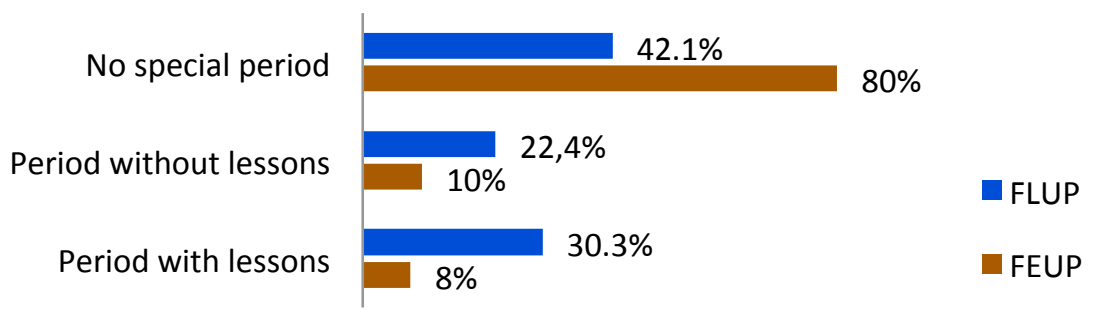

FIGURE 6. Period of access to electronic journals 
They also refer that they read more articles than they did some years before (72,7 at FLUP against 54,7 at FEUP). There is a significant association between Faculty and the number of read articles $(\chi 2(1)=4,499, p=0,034)$ (Figure 7)

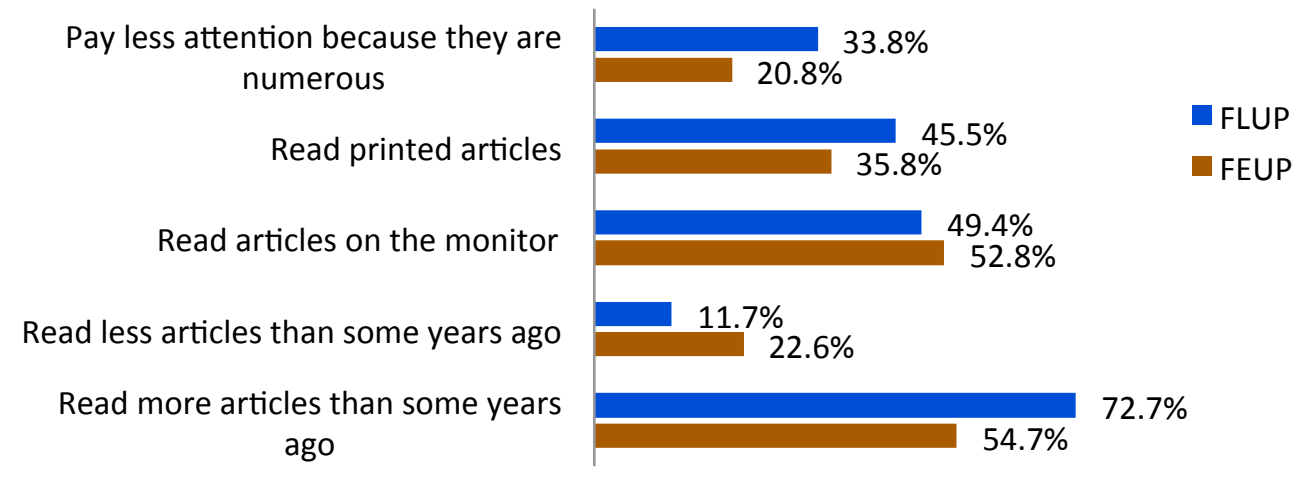

FIGURE 7. The reading of articles

At the Faculty of Arts and Humanities normally they don't use references managers $(68,9 \%)$ like in FEUP where they use for instance Mendeley, End note, and Zotero, more frequently. There is a significant association between Faculty and the use of references managers $(\chi 2(1)=11,681, p=0,020)$ (Figure 8)

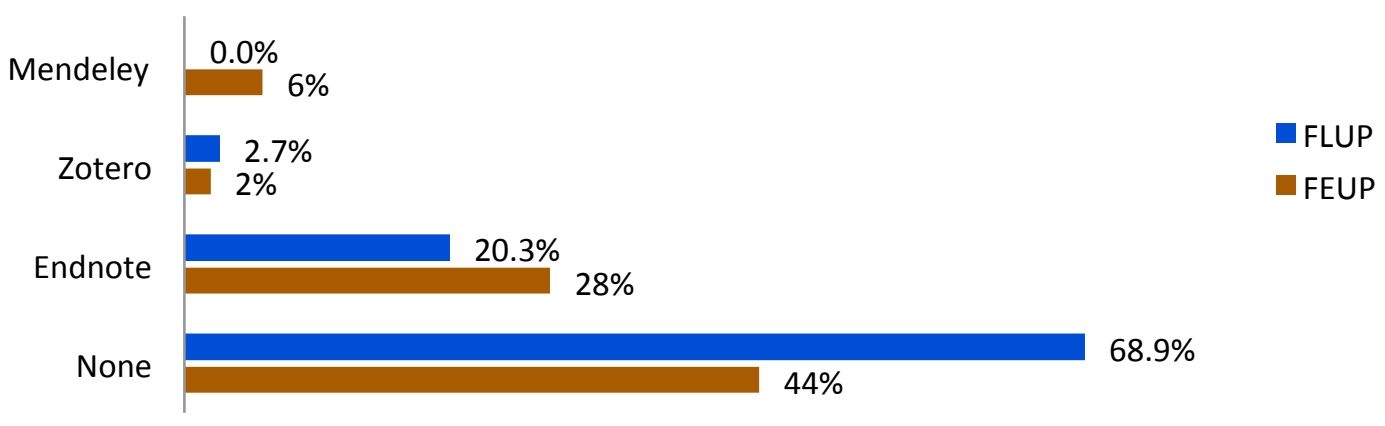

FIGURE 8. The reading of articles

\section{DISCUSSION}

The aim of this study was to analyse the differences in the use of electronic journals between teachers and researchers of two different faculties from the University of Porto and from two different areas of knowledge Engineering (FEUP) and Human and Social Sciences (FLUP).

According to results, teachers and researchers from the FLUP are more close to the use of the printed journals than those from FEUP. These last teachers/researchers see more advantages in using electronic journals than their pairs from FLUP although they refer knowing the resources used in electronic journals.

For teachers/researchers from FLUP the greater availability of resources and the economy of time are the two main reasons for using electronic journals. Researchers from FEUP refer the easy way to access information using electronic journals.

Results however show that researchers of both faculties prefer searching on Google and other web search engines than on data bases. It is interesting to note that, the site of the library of the faculty was used with more frequency by researchers from FLUP. As Pinelli (1991) referred Engineers use libraries less frequently and use only information systems oriented for them. 
In terms of the frequency of the use of electronic journals, teachers/researchers from FEUP use them diary or weekly and do not have any specific period to consult this format. On the other hand, the teachers and researchers from FLUP prefer to use the electronic journals weekly and in the period with lessons.

The majority of teachers and researchers from the two faculties read the articles on the monitor and read more articles than they did some years ago. Anyway most of teachers/researchers from FLUP do not use any specific software to manage their references.

According to these results, one can say that teachers/researchers from FEUP are more practical and prefer to use electronic journals because of the facility of access and also because they recognize the many advantages that this format means. Teachers and researchers from FLUP use the electronic journals to save time and prefer to use them during the period of lessons. In fact the preference demonstrated by researchers "reflects the prestige or value that researchers ascribe to various channels of communication and dissemination" of knowledge (Muller, 2005).

Despite the differences found, in both cases teachers and researchers have a good knowledge about electronic journals and recognize the advantages this format brings to their work.

\section{CONCLUSION}

This study analyses the use of electronic journals by teachers and researchers from two different faculties from the University of Porto, Portugal. In fact, journals are very important in the scientific process of communication which has undergone many developments over the years. Thus, understanding how electronic journals affect the ways of accessing knowledge by these researchers is fundamental as it is nowadays the usual means of disclosing knowledge in all areas.

In conclusion, the study reveals that teachers and researchers from the two faculties are very accustomed to the use of electronic journals. However, there appears to be some differences that may express the specificity of each scientific area and of the way of doing research. This is also related to different needs of information.

\section{REFERENCES}

1. A. Castillo, and M. C. Carretón, Investigación en Comunicación: Estudio bibliométrico de las Revistas de Comunicación en España. (Comunicación y sociedad, Madrid, 2010) 23 (2):289-327.

2. A. J. Meadows, Communication in science. (London, Butterworths, 1974).

3. A. M. Silva, A Informação. Da Compreensão Do Fenómeno E Construção Do Objecto Científico. (Edições Afrontamento, 2006).

4. C. R. S. Barbalho, Periódicos Científicos em formato eletrônico: elementos para sua avaliação. (Proceedings of XXVIII Congresso Brasileiro de Ciências da Comunicação. Rio de Janeiro: Intercom - Sociedade Brasileira de Estudos Interdisciplinares da Comunicação, 2005).

5. E. M. Menezes and V. Couzinet, $O$ interesse das revistas brasileiras e francesas de biblioteconomia e ciências da informação pela revista eletrônica no período de 1990-1999 (1999).

6. I. R. C. Stumpf, Passado e futuro das revistas científicas. (Ciência da Informação, Brasília, v. 25, n. 3, 1998).

7. M. Martínez-Silveira and N. Oddone, Necessidades e Comportamento Informacional: Conceituação e Modelos. (Ci. Inf., Brasília 36, 2007) pp. 118-27.

8. S. Herner, Information gathering habits of workers in puré and applied science. (Ind. Eng. Chem., 1954) v. 46, pp. 228-236.

9. S. P. M. Muller, A publicação da ciência: áreas científicas e seus canais preferenciais. (Datagramazero, v.06, n.1, fev. 2005).

10. T. D. Wilson, On User Studies and Information Needs. (Journal of Documentation, 1981).

11. T. E. Pinelli, The Information: Seeking Habits and Practices of Engineers. (Information Seeking and Communicating Behavior of Scientists and Engineers: Haworth Press, 1991). 